\title{
Weathering Features of A Five-Story Stone Pagoda Compared To Its Quarrying Site In Geumgolsan Mountain, Korea
}

\author{
Young Hoon Jo \\ Kongju National University \\ Chan Hee Lee ( $\nabla$ chanlee@kongju.ac.kr) \\ Kongju National University https://orcid.org/0000-0001-5572-0767
}

\section{Research Article}

Keywords: Weathering feature, Quarrying site, Lithic tuff, Material characteristic, Five-story stone pagoda at Geumgolsan Mountain

Posted Date: August 12th, 2021

DOI: https://doi.org/10.21203/rs.3.rs-771289/v1

License: (i) This work is licensed under a Creative Commons Attribution 4.0 International License. Read Full License

Version of Record: A version of this preprint was published at Environmental Earth Sciences on March 1st, 2022. See the published version at https://doi.org/10.1007/s12665-022-10303-1. 


\section{Abstract}

Understanding the long- and short-term weathering features according to rock type is very important for maintaining the original form of stone heritages. In this study, the material characteristics of a deteriorated five-story stone pagoda were compared with those of fresh rocks from its quarrying site at nearby Geumgolsan Mountain, Korea to diagnose the degree of damage and develop a comprehensive interpretation of the weathering mechanism. The stone pagoda was built from lithic tuff comprising pumice and phenocrysts such as quartz, K-feldspar, plagioclase, and mica based on plagioclase substrates; the mineralogical and geochemical characteristics are similar to those of the fresh rocks. The lithic tuff of the stone pagoda demonstrated a low ultrasonic velocity of $2863 \mathrm{~m} / \mathrm{s}$ and a high water absorption rate and porosity of $9.5 \%$ and $19.2 \%$, respectively, which are poorer than the physical properties of the fresh rocks (i.e., ultrasonic velocity of $3336 \mathrm{~m} / \mathrm{s}$, water absorption rate of $8.65 \%$, and porosity of $17.83 \%$ ). The lithological characteristics and physical properties demonstrated a considerable influence on the weathering and stability of the stone pagoda. In particular, fragments of relatively weak pumice detached from the original rock to form cavities of various sizes. These cavities introduced moisture within the rock, which produced oxides and hydroxides of iron and manganese. In addition, contaminants such as dust, salt crystals, clay minerals, and microorganisms adhering to the surface of the stone pagoda accelerated its physical, chemical, and biological weathering. The results of this study will be important for realizing the stable and long-term conservation of the five-story stone pagoda at Geumgolsan Mountain.

\section{Introduction}

Because of its strength, rock has traditionally been widely used to make buildings, monuments, artifacts, and tools. In Western cultures, rock was mainly used as a building material; in Eastern cultures, however, wooden buildings prevailed, and rock was mostly used for monuments such as pagodas, steles, and Buddha statues. Despite the different applications, the excellent durability of rock led to its wide use by various cultures in stone buildings and monuments that are exposed to the outdoors. In general, rocks have undergone millions of years of weathering throughout their geological history. The long-term weathering features by rock type are the basis for understanding the natural weathering mechanism of stone heritages. However, stone heritages undergo changes from their original form not only because of natural weathering but also because of environmental impacts (Vidal et al. 2019), climate change (Kim 2016; Zhang et al. 2019), structural deformation (Jo and Lee 2016; Kim et al. 2021), and intentional damage (Gomes et al. 2017). In this context, Fookes et al. (1971) emphasized the importance of understanding the short-term weathering resistance and damage potential of rocks for conserving the original forms of stone heritages.

In an effort to establish a systematic conservation system for stone heritages, various studies have focused on identifying the material characteristics of stone heritages and the causes of damage (Smith et al. 2008; Patil and Kasthurba 2020). In the past several decades, various methodologies including damage mapping have been applied to diagnosing the condition of stone heritages (Theodoridou and Török 2019; Randazzo et al. 2020). Various nondestructive testing methods such as ultrasonic measurement (Jo et al. 2012; Chen et al. 2020), infrared thermography (Avdelidis and Moropoulou 2004; Jo and Lee 2014), hyperspectral image analysis (Chun et al. 2015), and sensor measurement (Park et al. 2021) as well as simple testing (Cabrera et al. 2021) have been established as essential for diagnosing the conditions of and degree of damage to stone heritages.

Various conservation studies have been conducted on a five-story stone pagoda at Geumgolsan Mountain in Korea, for which the stone members are in very poor condition and require an urgent safety diagnosis. In the present study, various techniques were applied to analyze the material characteristics of the stone pagoda, which were compared with the material characteristics of fresh rock from the quarrying site of provenance to identify the weathering features. The present state of surface damage to the stone pagoda was mapped through visual observation and simple testing, and the microstructure and components of contaminants were analyzed. Based on the weathering features and damage diagnosis, a comprehensive interpretation of the weathering mechanism was developed, which should help facilitate the conservation of the stone pagoda.

\section{Study Object And Methodology}

\subsection{Study object}

The Cultural Heritage Administration in Korea has designated approximately 571 stone monuments and structures as national heritages as of 2020. These stone heritages range from petroglyphs and dolmens dating to the prehistoric period to stone pagodas, 
stone Buddha statues, stone steles, rock-carved Buddha statues, stone stupas, and flagpole supports dating to various historical periods. In particular, stone pagodas (34.0\%) account for the highest proportion of current stone heritages.

The five-story stone pagoda at Geumgolsan Mountain (Korean Treasure No. 529) was the object of this study. The pagoda is located in Jindo-gun, which is the southernmost tip of the Korean peninsula and is bordered by several straits and hundreds of islands (Fig. 1). This area has a warm climate and large amounts of precipitation; it has historically been a strategically important location between the West and South Seas. The stone pagoda was built on flat ground, and it is located on the right side of an elementary school and in front of Geumgolsan Mountain, which is an outcropping of tuff that rises $193 \mathrm{~m}$ above sea level. The construction date of the stone pagoda is not yet known, but it is estimated to have been after the middle of the Goryeo dynasty (918-1392 CE) owing to its low base and high first-story body. This stone pagoda has experienced severe deterioration due to physical, chemical, and biological weathering. A scientific approach to characterizing the weathering features and diagnosing the damage is necessary to ensure the conservation of the stone pagoda.

\subsection{Methodology}

Material analysis, mapping of the conservation conditions, and nondestructive ultrasonic testing were conducted to determine the weathering characteristics of the stone pagoda and diagnose the degree of damage. The material analysis was performed on rock fragments exfoliated from the stone pagoda and rocks collected from the quarrying site of provenance. A polarizing microscope (Eclipse E600W, Nikon) and X-ray diffraction (D/Max-2000, Rigaku) were used to analyze the mineralogical characteristics. Then, an inductively coupled plasma optical emission spectrometer (FUS-ICP) and neutron activation analysis system (INAA) operated by Actlabs in Canada were used to quantitatively analyze the geochemical characteristics (i.e., main components, trace elements, and rare earth elements). Scanning electron microscopy (SEM, MIRA3 LMH, TESCAN) was used to observe the microstructures of rocks and discolored contaminants, and energy-dispersive spectrometry (EDS, Quantax 200, Bruker) was used to detect the components of certain structures.

The conservation condition of the stone pagoda was analyzed by mapping the types of damage through visual inspection and simple testing. First, damage to the stone pagoda that could be observed with the naked eye was classified as structural crack, hair crack, delamination, scaling, fragmentation, cavity, brown discoloration, black discoloration, or biological colonization (ICOMOS-ISCS 2008). The discoloration and biological colonization were divided into five grades according to the visibility of the original rock and microbial coverage, respectively. Simple tools such as a scale, tapping tool, and caliper were used to supplement the objectivity of the damage type classification and mapping. The digital mapping method and quantitative evaluation of the damage types were based on the approach presented by Jo \& Lee (2011).

Ultrasonic measurement (PUNDIT Plus, CNS Farnell) is a nondestructive testing method, and it was used to quantitatively measure the degree of weathering of the stone pagoda. To establish the measurement conditions for the stone pagoda, which had severe surface irregularities, the intensity of the received waveform according to the ultrasonic frequency and transducer distance was analyzed in advance to calibrate the system. For the transducer, an exponential type with a frequency of $54 \mathrm{kHz}$ was selected because it is not significantly affected by irregularities and porous materials, and a probe correction factor of 1.08 as suggested by Lee \& Jo (2017) was applied. Rubber clay without residue was used as the coupling medium.

The ultrasonic transducers were arranged for indirect measurement at a distance of $200 \mathrm{~mm}$. In particular, the difference between the ultrasonic velocities of the direct measurement $(\mathrm{Vd})$ and indirect measurement $(\mathrm{Vi})$ was corrected by applying a linear regression equation $\left(\mathrm{Vd}=1.355 \mathrm{Vi}-71.394, \mathrm{R}^{2}=0.91\right)$ at measurement points on the body of the five-story pagoda. The corrected ultrasonic velocities were projected on the elevation of the stone pagoda to identify members with relatively weak physical properties. In addition, ultrasonic velocities were obtained for fresh rocks from the provenance site at Geumgolsan Mountain, and the weathering index suggested by lliev (1966) was used to calculate the weathering grade.

\section{Material And Weathering Characteristics 3.1. Geological and rock distribution}

The geology of the Korean peninsula is very diverse, and its rocks are often well exposed in the mainly mountainous terrain. More than half of the peninsula comprises granite and granite gneiss. The former mainly intruded during the Triassic, Jurassic, and 
Cretaceous periods, whereas the latter formed because of metamorphism and granitization of sedimentary rocks during the Precambrian. In addition, volcanic rocks can be found mainly in strata from the Cretaceous period of the Mesozoic era in the southern part of the Korean peninsula and are exposed as tuff, andesite, and rhyolite. The geological characteristics of the Korean peninsula are closely related to the materials and construction techniques used to shape the stone heritages of the country (Lee and Jo, 2016).

The geology of the area around the five-story stone pagoda was formed by volcanic activity during the Cretaceous period, and it mainly comprises quartz porphyry, porphyry tuff, acidic tuff, and porphyrite (Fig. 2). Geumgolsan Mountain comprises acidic tuff, which is the same material used to build the stone pagoda. In general, tuff is soft, highly porous, and absorbent, and it has the advantage of being easily dressed. Therefore, tuff has long been widely used as a material for buildings and stonework. The stone pagoda appears to have been constructed from tuff because of its proximity to Geumgolsan Mountain and the ease of dressing this material. This is evidenced by the many traces of quarrying that have been observed in large outcrops on Geumgolsan Mountain.

\subsection{Lithological characteristics}

The five-story stone pagoda was built from lithic tuff that is light yellow to light gray. The rock contains many fragments of light green pumice with sizes of several millimeters to several centimeters (Fig. 3a). Because pumice has weak physical properties compared to the rock substrate, these fragments detached from the original rock of the stone pagoda owing to physical and chemical weathering (Fig. 3b). A horizontal bedding structure was clearly observed for the pagoda, which was attributed to the material characteristics of lithic tuff (Fig. 3c). In general, masonry structures require a horizontal bedding to prevent cracking due to compressive forces. However, some members of the stone pagoda exhibited a vertical bedding structure around which microcracks were distributed (Fig. 3d); this was presumed to indicate that the material characteristics were not sufficiently considered at the time of construction.

To supplement the petrographic features of the stone pagoda, a slab analysis was conducted on lithic tuff collected from Geumgolsan Mountain. These samples clearly contained pumice, which was not well observed on the surface of the stone pagoda, and phenocrysts such as quartz, plagioclase, K-feldspar, and biotite were identified. In addition, iron-containing minerals were discolored to light brown because of chemical weathering, and dark-colored contaminants caused by manganese hydroxide were partially extracted from the surface (Fig. 3e).

The mineral compositions of the lithic tuff of the stone pagoda and Geumgolsan Mountain were analyzed by using a polarizing microscope (Fig. 4a) and X-ray diffraction (Fig. 4b). The results showed that the rocks contained pumice and phenocrysts such as quartz, K-feldspar, plagioclase, and mica based on plagioclase substrates. In modal analysis based on the mineral composition, the rocks were plotted in the area corresponding to lithic tuff with a composition of $36.2-42.4 \%$ glass, $5.8-9.2 \%$ crystal, and $51.9-57.1 \%$ rock fragment (Fig. 4c).

The main components of the lithic tuff in the stone pagoda and Geumgolsan Mountain were plotted on total alkalis-silica (TAS) and $\mathrm{SiO}_{2}-\left(\mathrm{Zr} / \mathrm{TiO}_{2} \times 0.001\right)$ classification diagrams (Figs. $\left.4 \mathrm{~d}, 4 \mathrm{e}\right)$. The rocks from the two sources were in the area corresponding to rhyolite. In addition, the rocks showed almost the same trends in their geochemical characteristics regarding the major, rare earth, and compatible and incompatible elements (Fig. 4f). These results indicate that the stone pagoda and lithic tuff of Geumgolsan Mountain have a genetically common source.

\subsection{Weathering characteristics}

The soft and porous characteristics of lithic tuff are convenient for stone dressing but are also the main factors for the weak physical properties. In addition, the fragments of pumice cause differential weathering (Germinario and Török 2020), and the bedding structure causes cracks because of anisotropy (Wang et al. 2017). Therefore, a slab cross-sectional analysis and simple test of the physical properties were performed to examine the weathering characteristics of lithic tuff.

First, lithic tuff showing the same weathering tendencies as the stone pagoda was collected from Geumgolsan Mountain, and its cross-section was polished to produce a slab sample. The slab face comprised two weathered layers discolored to black and a fresh layer (Fig. 5). The outermost first weathering layer had cavities that formed because of the erosion or detachment of pumice, and the layer showed relatively severe discoloration because of oxides and hydroxides. The second weathering layer below the rock surface was discolored because of chemical weathering, similar to the surface layer, but pumice fragments remained within the layer. In the 
innermost fresh layer, the light green color of the original rock was maintained well without discoloration, and the pumice fragments remained within the layer. However, the pumice fragments were so soft that they could be detached even by fingernails.

The water absorption rate and porosity of a specimen detached from the stone pagoda and fresh rock from Geumgolsan Mountain were calculated to compare their physical properties (Fig. 6a). On average, the water absorption rate and porosity of the stone pagoda were $9.5 \%$ and $19.2 \%$, respectively, which were greater than the water absorption rate (8.6\%) and porosity $(17.8 \%)$ of the rock from Geumgolsan Mountain. Thus, the stone pagoda showed poorer physical properties than the fresh lithic tuff. To identify the weathering characteristics of the stone pagoda, fresh lithic tuff was submerged in distilled water for $24 \mathrm{~h}$ and dried at $105^{\circ} \mathrm{C}$ for another $24 \mathrm{~h}$. Then, the change in weight was measured (Fig. 6b). The lithic tuff showed relatively rapid changes in weight for one cycle and then gradually decreased in weight thereafter. The decrease in weight was attributed to weak minerals including pumice reacting with water, which cause them to dissolve partially or detach physically. After 5 days of submersion, the pumice in the lithic tuff detached and precipitated in the beaker. This indicates that the pumice is sensitive to moisture.

To examine the chemical weathering characteristics, SEM equipped with EDS was conducted on small samples of the stone pagoda. The pumice surface was observed to be covered with cubic sodium chloride crystals ( $\mathrm{Na} 34.3$ wt.\%, Cl 53.8 wt.\%) (Fig. 7a), which was attributed to the sea breeze because the stone pagoda is about $3 \mathrm{~km}$ from the ocean. In addition, the brown discoloration on the surface of the stone pagoda appears to have been caused by microcrystalline clay minerals and iron oxide (Fig. 7b) with some coexisting microcrystalline gypsum crystals (Figs. 7c and 7d). The maximum iron oxide content for the brown discoloration was 26.5 wt.\%. In contrast, the black discoloration consisted of diverse structures such as a thick crust of amorphous material (Figs. 7e and 7f), dendrites (Figs. 7g-7j), and acicular-columnar microtexture aggregates (Fig. 7k). EDS analysis showed that the black discoloration materials mainly comprised Mn (19.4-71.7 wt.\%) and Fe (1.2-26.5 wt.\%). High levels of Ca (13.7 wt.\%) and S (12.9 wt.\%) were detected in the acicular-columnar microtextures, which indicated the coexistence of gypsum crystals (Figs. 7l-7n). Clay minerals, dust, fine soil particles, and microorganisms were also identified.

\section{Damage Diagnosis}

\subsection{Conservation conditions}

The stone pagoda has been exposed to the outdoor environment since its construction, which has led to a complex pattern of various kinds of physical, chemical, and biological weathering. In particular, several hundred cavities can be observed with the naked eye; this has been attributed to the detachment of pumice fragments with sizes of several millimeters to several centimeters (Fig. 8a). In addition, cracks that are generally fine or parallel to the stone surface have developed in the bedding direction at the edge of the basement, and structural cracks have occurred on the south side of the fourth-story roof (Fig. 8b). Delamination and scaling mainly occurred on the sides of the members, and a significant degree of three- to five-layer scaling was observed on the south basement (Fig. 8c). Although fragmentation was identified in some of the roof and foundation stones, fragmentation does not appear to have caused structural deformation in general (Fig. 8d). Regarding chemical damage to the stone pagoda, brown and black discolorations were commonly observed, and the effects of diverse secondary contaminants were identified on the basement stone and roof support (Figs. 8e and 8f). In addition, biological colonization was observed throughout the stone pagoda. Various microorganisms such as algae, lichens, and bryophytes adhered to the stone surface as parasites, which resulted in black, green, and light gray colors. In particular, lichens were widely distributed on the bodies of each story and the upper parts of roof stones exposed to precipitation (Figs. 8g and 8h).

The damage map is commonly used to describe and record conservation conditions; it provides basic data for conservation conditions by symbolizing damage types and mapping their ranges. A damage map was created (Fig. 9) to visualize and quantify the conservation conditions of the stone pagoda. The main causes of damage to the stone pagoda were determined to be physical weathering such as delamination, scaling, and cavities; chemical weathering such as brown and black discoloration; and biological colonization such as lichens. In particular, all types of physical and chemical weathering except for biological colonization predominantly occurred on the west and south faces. The west face showed severe damage in terms of hair cracks (1.6), fragmentation ( $0.9 \%)$, and discoloration (38.9\%), while the south face showed severe damage in terms of delamination (9.6\%) and scaling (7.5\%). Cavities larger than $1 \mathrm{~cm}$ were observed on the east face. Biological colonization covered almost $100 \%$ of the north face.

\subsection{Ultrasonic measurement}


Because the ultrasonic velocity through a rock is sensitive to cracks, mineral decomposition, and voids, it is widely used to evaluate the degree of weathering of stone heritages (Lee and Jo 2016; Chen et al. 2020). In this study, the ultrasonic velocity was measured for each face of the stone pagoda, and the results were compared with those of fresh lithic tuff from Geumgolsan Mountain to calculate the relative weathering indices. The weathering index at each measurement point (167 points on the east face, 168 points on the west face, 167 points on the south face, and 164 points on the north face) were projected onto elevation views of the pagoda in the form of a contour map and was used to identify the overall weathering trends (Fig. 10). The ultrasonic velocities of the stone pagoda were $1551-3605 \mathrm{~m} / \mathrm{s}$ (average of $2741 \mathrm{~m} / \mathrm{s}$ ) on the east face, $924-4135 \mathrm{~m} / \mathrm{s}$ (average of $2820 \mathrm{~m} / \mathrm{s}$ ) on the west face, $893-$ $3610 \mathrm{~m} / \mathrm{s}$ (average of $2818 \mathrm{~m} / \mathrm{s}$ ), on the south face, and 1399-3950 m/s (average of $3025 \mathrm{~m} / \mathrm{s}$ ) on the north face. Overall, all faces showed a wide range of ultrasonic velocities, and the average ultrasonic velocity was highest on the north face. The average ultrasonic velocity for the entire stone pagoda was calculated to be $2863 \mathrm{~m} / \mathrm{s}$.

Iliev (1966) proposed a coefficient of weathering $(K)$ based on the rates of change in the ultrasonic velocities of fresh and weathered rocks. The $K$ value comprehensively considers influencing factors of the ultrasonic velocity that change with the degree of weathering (e.g., the density, porosity, expansion of microcracks, and degree of consolidation). The $K$ value continuously increases as the weathering degree becomes more severe, and it can be used to divide weathering into five grades. To calculate the $K$ value of the stone pagoda, ultrasonic velocities were measured at fresh outcrops (30 points) on Geumgolsan Mountain (i.e., the quarrying site of provenance). The ultrasonic velocity for the fresh rock was $3161-3863 \mathrm{~m} / \mathrm{s}$ with an average of $3336 \mathrm{~m} / \mathrm{s}$. These values were used to calculate the $K$ value and grade the weathering of the stone pagoda. The $K$ values of the stone pagoda were projected onto the elevation views for each face. All faces were undergoing some weathering, but most measurement points graded as slightly weathered $(57.4 \%)$ or moderately weathered $(29.0 \%)$. Some measurement points graded as fresh or highly weathered. The average $K$ value for the stone pagoda was 0.14 . Based on the distribution of $K$ values, the basement and fourth-story roof are relatively vulnerable on the east face, and the first-floor body shows severe weathering on the west and south faces. On the north face, although the fourth- and fifth-story roofs have poor physical properties, the overall conservation condition is good compared to the other faces.

\section{Weathering Mechanism Interpretation}

The five-story stone pagoda was built from lithic tuff with a vitric substrate containing pumice in large quantities. This stone has the same lithological characteristics as rocks from the nearby Geumgolsan Mountain. The lithic tuff of the stone pagoda has a low ultrasonic velocity $(2863 \mathrm{~m} / \mathrm{s})$ and a high water absorption rate $(9.5 \%)$ and porosity $(19.2 \%)$. These are poorer physical properties compared to those of fresh rock from Geumgolsan Mountain, which has an ultrasonic velocity, water absorption rate, and porosity of $3336 \mathrm{~m} / \mathrm{s}, 8.7 \%$, and $17.8 \%$, respectively. This demonstrates that the stone pagoda has undergone continuous weathering since construction. In contrast, the bedrock of Mudeungsan National Park (UNESCO Global Geopark) contains tuff from the Cretaceous period and has an ultrasonic velocity, water absorption rate, and porosity of $4948 \mathrm{~m} / \mathrm{s}, 0.4 \%$, and $1.0 \%$, respectively (Noh et al. 2020). This clearly demonstrates the severity of the degree of weathering experienced by the stone pagoda. Therefore, although the stone pagoda was constructed from rocks in Geumgolsan Mountain owing to the close proximity and convenience for dressing, these rocks had low durability from the time of construction. According to historical data, the stone pagoda appears to have been constructed around $1300 \mathrm{CE}$. Thus, the difference in average ultrasonic velocity $(473 \mathrm{~m} / \mathrm{s})$ between the stone pagoda and fresh rock from Geumgolsan Mountain represents the degree of physical weathering over about 700 years.

Based on the above results, the weathering mechanism for the stone pagoda was interpreted to be as follows. The lithological characteristics and physical properties had a considerable influence on the weathering and stability of the stone pagoda. In particular, weak pumice fragments detached from the original rock as the physical and chemical weathering progressed, which formed cavities of various sizes that not only degraded the physical properties of the rock but also acted as passageways for the inflow and transfer of moisture. In addition, they provided places for contaminants and microorganisms to collect and thus accelerated secondary damage. The moisture introduced through the cavities accelerated the weathering of minerals by reacting with the large amounts of iron and manganese within the tuff to produce iron oxide, iron hydroxide, manganese oxide, and manganese hydroxide. In addition, contaminants such as dust, salt crystals, clay minerals, and microorganisms adhered to the surface of the stone pagoda, which accelerated the chemical and biological weathering over time. In particular, the sea breeze from the nearby ocean ( $3 \mathrm{~km}$ away) and lime used as a repair material in the past formed $\mathrm{NaCl}$ and $\mathrm{CaSO}_{4}$ crystals that reacted with the moisture. These oxides, hydroxides, and salt crystals increased the pressure inside the rock, which caused cracks and blistering to develop. Diverse chemically weathered 
materials were deposited in the cracks and blisters, which resulted in brown and black discolorations. Freeze-thaw action in winter may have caused scaling zones to expand and eventually lead to scaling-off of the stone members. As such, the major factors for the weathering of the five-story stone pagoda were attributed to the weak physical properties of lithic tuff with pumice fragments. In addition, the resulting cracks, delamination, scaling, blackening, and biological colonization led to the complex damage patterns of the stone pagoda. Although these factors sometimes acted individually, most appeared to interact with each other to accelerate the damage to the stone pagoda. These findings are important for ensuring the stable and long-term conservation of this pagoda and may help with establishing a scientific conservation system for similar stone heritages.

\section{Conclusion}

1. The five-story stone pagoda was built from lithic tuff containing pumice and phenocrysts such as quartz, K-feldspar, plagioclase, and mica based on plagioclase substrates. The stone pagoda and lithic tuff of Geumgolsan Mountain have similar geochemical characteristics, which indicate a genetically common source.

2. The slab face of the lithic tuff from the stone pagoda comprised two weathered layers and a fresh layer. The weathered layers were discolored to black and brown because of the complex reaction of microcrystalline clay minerals, iron oxide, manganese hydroxide, amorphous materials, microorganisms, salt crystals, dendrites, and acicular-columnar microtexture aggregates. In particular, the outermost first weathering layer had cavities due to erosion or the detachment of pumice fragments. For this reason, the stone pagoda showed poorer physical properties than the fresh lithic tuff from Geumgolsan Mountain.

3. The stone pagoda underwent physical damage such as delamination, scaling, and cavities; chemical weathering such as brown and black discolorations; and biological colonization such as lichens. In particular, the west face showed severe damage in terms of hair cracks (1.6), fragmentation (0.9\%), and discoloration (38.9\%), while the south face showed severe delamination (9.6\%) and scaling $(7.5 \%)$. Biological colonization covered almost $100 \%$ of the north face.

4. The average ultrasonic velocity of the entire stone pagoda was calculated to be $2863 \mathrm{~m} / \mathrm{s}$. The average ultrasonic velocity was lowest on the east face. The coefficients of weathering calculated from the ultrasonic velocity indicated that most measurement points on the pagoda were slightly weathered $(57.4 \%)$ or moderately weathered $(29.0 \%)$. The average coefficient of weathering was 0.14 . The difference between the average ultrasonic velocities $(473 \mathrm{~m} / \mathrm{s})$ of the stone pagoda and fresh rock from Geumgolsan Mountain represents the degree of physical weathering over about 700 years.

5. The weathering of the stone pagoda is closely related to the weak physical properties of its building material. The pumice fragments detached from the original rock, which formed cavities of various sizes. The cavities introduced moisture, which produced oxides and hydroxides of iron and manganese. In addition, contaminants such as dust, salt crystals $\left(\mathrm{NaCl}, \mathrm{CaSO}_{4}\right)$, clay minerals, and microorganisms adhered to the surface of the stone pagoda, which accelerated physical, chemical, and biological weathering over time. This interpretation of the weathering mechanism is important for the stable and long-term conservation of this stone pagoda and may help with establishing a scientific conservation system for similar stone heritages.

\section{References}

1. Avdelidis NP, Moropoulou A (2004) Applications of infrared thermography for the investigation of historic structures. Journal of Cultural Heritage 5:119-127. https://doi.org/10.1016/j.culher.2003.07.002

2. Cabrera V, Yustres Á, López-Vizcaíno R, Merlo Ó, Ruiz M, Torrero E, Navarro V (2021) Determination of the hygric properties of the heritage stone of the Cathedral of Cuenca through the water absorption by capillarity test. Journal of Cultural Heritage 48:186195. https://doi.org/10.1016/j.culher.2020.11.009

3. Chen X, Qi XB, Xu ZY (2020) Determination of weathered degree and mechanical properties of stone relics with ultrasonic CT: A case study of an ancient stone bridge in China. Journal of Cultural Heritage 42:131-138. https://doi.org/10.1016/j.culher.2019.08.007

4. Chun YG, Lee MS, Kim YR, Lee MH, Choi MJ, Choi KH (2015) Utilization of hyperspectral image analysis for monitoring of stone cultural heritages. Journal of Conservation Science 31:395-402. https://doi.org/10.12654/JCS.2015.31.4.07

5. Fookes PG, Dearman WR, Franklin JA (1971) Some engineering aspects of rock weathering with field examples from Dartmoor and elsewhere. Q J Eng GeolHydrogeol 4:139-185. https://doi.org/10.1144/GSL.QJEG.1971.004.03.01

Page $7 / 15$ 
6. Germinario L, Török Á (2020) Surface Weathering of Tuffs: Compositional and microstructural changes in the building stones of the medieval castles of Hungary. Minerals 10:376. https://doi.org/10.3390/min10040376

7. Gomes V, Dionísio A, Pozo-Antonio JS (2017) Conservation strategies against graffiti vandalism on Cultural Heritage stones: Protective coatings and cleaning methods. Prog Org Coat 113:90-109. http://dx.doi.org/10.1016/j.porgcoat.2017.08.010

8. ICOMOS-ISCS (2008) Illustrated glossary on stone deterioration patterns. Champigny/Marne, France

9. lliev IG (1966) An attempt to estimate the degree of weathering of intrusive rocks from their physico-mechanical properties. In: Proceedings of the first congress of the international society of rock mechanics, pp.109-114

10. Jo YH, Lee $\mathrm{CH}$ (2011) Making method of deterioration map and evaluation techniques of surface and three-dimensional deterioration rate for stone cultural heritage. Journal of Conservation Science 27:251-260

11. Jo YH, Lee CH (2014) Quantitative modeling and mapping of blistering zone of the Magoksa Temple stone pagoda (13th century, Republic of Korea) by graduated heating thermography. Infrared Phys Technol 65:43-50. http://dx.doi.org/10.1016/j.infrared.2014.02.011

12. Jo YH, Lee CH (2016) Displacement analysis of five-story stone pagoda in Geumgolsan Mountain, Jindo, using terrestrial laser scanning. Indian Journal of Science Technology 9:1-6. http://dx.doi.org/ 10.17485/ijst/2016/v9iS1/109835

13. Jo YH, Lee CH, Chun YG (2012) Material characteristics and deterioration evaluation for the 13th century Korean stone pagoda of Magoksa temple. Environ Earth Sci 66:915-922. https://doi.org/10.1007/s12665-011-1301-8

14. Kim J (2016) Climate change impact on Korean stone heritage: research trends and prospect. Journal of Conservation Science 32:437-448. http://dx.doi.org/10.12654/JCS.2016.32.3.14

15. Kim SH, Lee CH, Jo YH (2021) Behavioral characteristics and structural stability of the walls in the ancient Korean Royal Tombs from the sixth century Baekje Kingdom. Environ Earth Sci 79:81. https://doi.org/10.1007/s12665-020-8819-6

16. Lee CH, Jo YH (2016) Stone heritage of the Republic of Korea. In: Kato S, Reedman A, Shimazaki Y, Uchida T, Ngoc NTM, Surinkum A (eds) Stone heritage of east and southeast Asia. CCOP, pp 79-103

17. Lee $\mathrm{CH}$, Jo YH (2017) Correlation and correction factor between direct and indirect methods for the ultrasonic measurement of stone samples. Environ Earth Sci 76:477. https://doi.org/ 10.1007/s12665-017-6810-7

18. Noh J, Jang H, Lim C, Hwang N, Kang SS (2020) Engineering characteristics of Mudeungsan tuff and Ipseok-dae columnar joints. The Journal of Engineering Geology 30:161-173. https://doi.org/10.9720/kseg.2020.2.161

19. Park JH, Park ST, Lee CH (2021) Structural stability and microscale behaviors of the fortress wall from the sixth century Baekje Kingdom in ancient Korea. Heritage Science 9:65. https://doi.org/10.1186/s40494-021-00539-8

20. Patil SM, Kasthurba AK (2021) Weathering of stone monuments: Damage assessment of basalt and laterite. Materials Today: Proceedings 43:1647-1658. https://doi.org/10.1016/j.matpr.2020.10.022

21. Randazzo L, Collina M, Ricca M, Barbieri L, Bruno F, Arcudi A, La Russa MF (2020) Damage Indices and Photogrammetry for Decay Assessment of Stone-Built Cultural Heritage: The Case Study of the San Domenico Church Main Entrance Portal (South Calabria, Italy). Sustainability 12:5198. https://doi.org/10.3390/su12125198

22. Smith BJ, Gomez-Heras M, McCabe S (2008) Understanding the decay of stone-built cultural heritage. Prog Phys Geogr 32:439461. https://doi.org/10.1177/0309133308098119

23. Theodoridou M, Török Á (2019) In situ investigation of stone heritage sites for conservation purposes: a case study of the Székesfehérvár Ruin Garden in Hungary. Progress in Earth Planetary Science 6:1-14. https://doi.org/10.1186/s40645-019-0268z

24. Vidal F, Vicente R, Silva JM (2019) Review of environmental and air pollution impacts on built heritage: 10 questions on corrosion and soiling effects for urban intervention. Journal of Cultural Heritage 37:273-295. htps://doi.org/10.1016/j.culher.2018.11.006 1296-2074

25. Wang M, Tan C, Meng J, Yang B, Li Y (2017) Crack classification and evolution in anisotropic shale during cyclic loading tests by acoustic emission. J Geophys Eng 14:930-938. https://doi.org/10.1088/1742-2140/aa6f24

26. Zhang G, Gong C, Gu J, Katayama Y, Someya T, Gu JD (2019) Biochemical reactions and mechanisms involved in the biodeterioration of stone world cultural heritage under the tropical climate conditions. International Biodeterioration Biodegradation 143:104723. https://doi.org/10.1016/j.ibiod.2019.104723 
Tables

Table 1. Component results from energy-dispersive spectrometry for blackened samples of the stone pagoda (wt.\%).

\begin{tabular}{|c|c|c|c|c|c|c|c|c|c|c|c|c|c|c|}
\hline Points & C & 0 & $\mathrm{Na}$ & $\mathrm{Mg}$ & $\mathrm{Al}$ & $\mathrm{Si}$ & $P$ & $S$ & $\mathrm{Cl}$ & $\mathrm{K}$ & $\mathrm{Ca}$ & $\mathrm{Mn}$ & $\mathrm{Fe}$ & Total \\
\hline a & - & 11.94 & 34.30 & - & - & - & - & - & 53.76 & - & - & - & - & 100.00 \\
\hline$b$ & 14.05 & 44.11 & - & 0.35 & 2.72 & 12.92 & 1.36 & - & - & 0.52 & - & - & 23.97 & 100.00 \\
\hline c & 13.82 & 49.64 & - & - & 1.71 & 2.18 & - & 15.41 & - & - & 17.24 & - & - & 100.00 \\
\hline d & 14.44 & 51.08 & - & - & 1.67 & 2.93 & - & 13.73 & - & - & 16.15 & - & - & 100.00 \\
\hline e & 3.87 & 39.09 & 0.53 & 0.87 & 5.61 & 19.35 & - & 0.60 & 1.67 & 2.17 & - & 20.67 & 5.57 & 100.00 \\
\hline$f$ & 5.79 & 31.76 & - & 1.53 & 6.85 & 16.40 & - & - & 2.03 & 2.34 & - & 24.68 & 8.62 & 100.00 \\
\hline g & 2.03 & 30.23 & 0.43 & 0.33 & 2.54 & 5.83 & - & 0.63 & 0.65 & 2.22 & - & 51.81 & 3.30 & 100.00 \\
\hline $\mathrm{h}$ & 4.86 & 40.98 & 5.15 & - & 8.54 & 28.56 & - & 0.53 & - & 0.77 & 0.30 & 9.07 & 1.24 & 100.00 \\
\hline i & - & 45.15 & - & 2.06 & - & - & - & - & - & - & 1.82 & 50.97 & - & 100.00 \\
\hline j & - & 23.26 & - & 0.84 & - & 2.21 & - & - & - & - & 1.95 & 71.74 & - & 100.00 \\
\hline k & 2.07 & 44.21 & 0.70 & - & 2.17 & 20.41 & - & - & 1.54 & 2.19 & 1.81 & 19.39 & 5.51 & 100.00 \\
\hline I & - & 17.20 & - & - & 1.22 & 2.72 & - & 3.06 & - & - & 5.62 & 70.18 & - & 100.00 \\
\hline $\mathrm{m}$ & 5.47 & 56.58 & - & - & 3.22 & 6.19 & - & 12.89 & - & 1.92 & 13.73 & - & - & 100.00 \\
\hline $\mathrm{n}$ & - & 31.27 & 1.63 & 1.08 & 8.65 & 20.43 & - & - & 2.05 & 3.69 & 1.13 & 3.61 & 26.46 & 100.00 \\
\hline
\end{tabular}

Table 2. Ultrasonic velocity for each face and average weathering coefficient and grade of the stone pagoda compared to fresh lithic tuff from Geumgolsan Mountain

\begin{tabular}{llllllll} 
Points & \multicolumn{3}{l}{ Velocity $(\mathrm{m} / \mathrm{s})$} & \multicolumn{2}{l}{ Total } \\
\cline { 2 - 8 } & East & West & South & North & Velocity $(\mathrm{m} / \mathrm{s})$ & Coefficient $(\mathrm{K})$ & Grade \\
\hline Ave. & 2,741 & 2,820 & 2,818 & 3,025 & 2,863 & 0.14 & Slightly weathered \\
\hline Min. & 1,551 & 924 & 893 & 1,399 & 893 & 0.73 & Completely weathered \\
\hline Max. & 3,605 & 4,135 & 3,160 & 3,950 & 4,135 & 0.00 & Fresh
\end{tabular}

Figures 

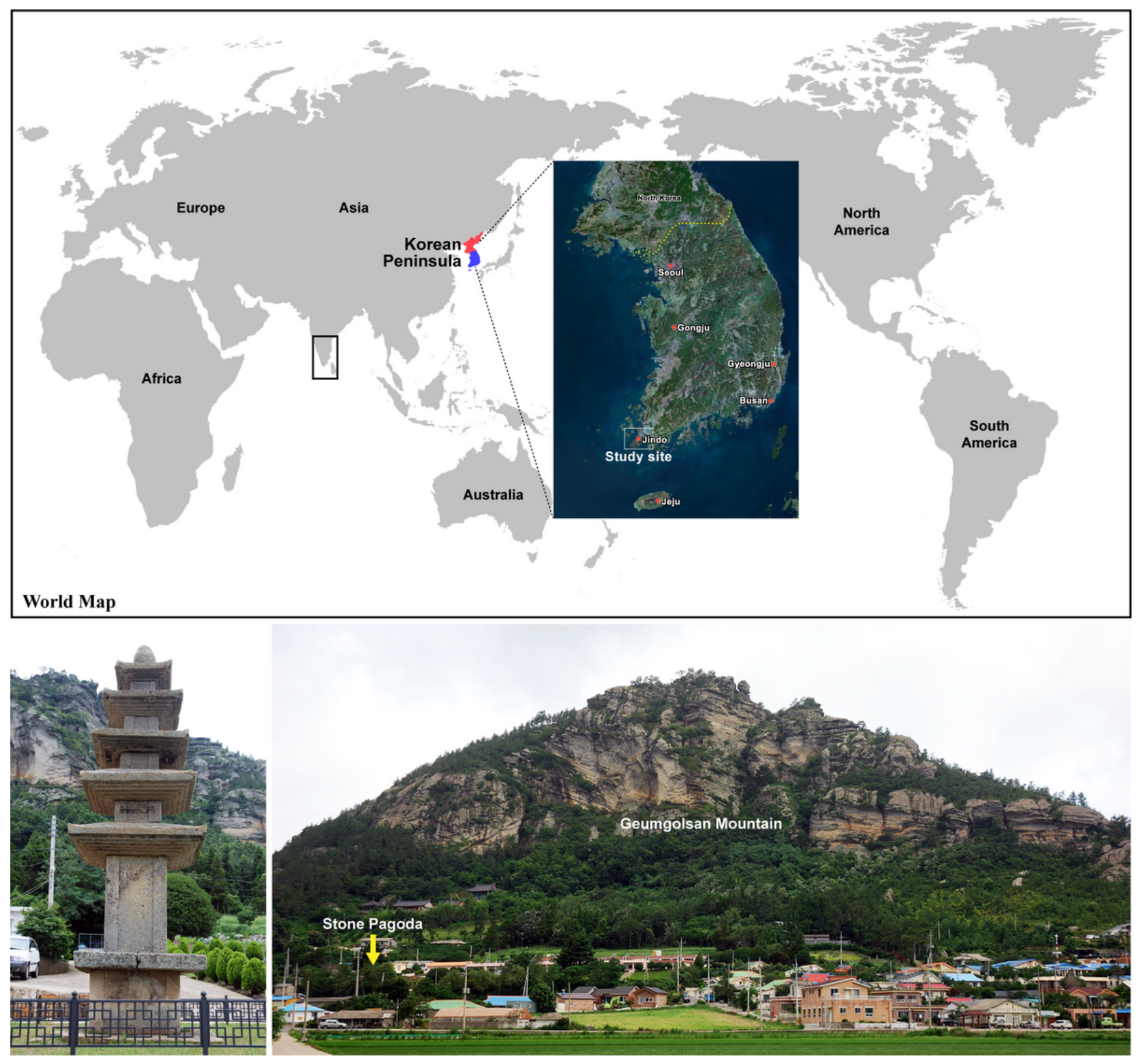

\section{Figure 1}

Location and appearance of the five-story stone pagoda at Geumgolsan Mountain, Jindo-gun. 


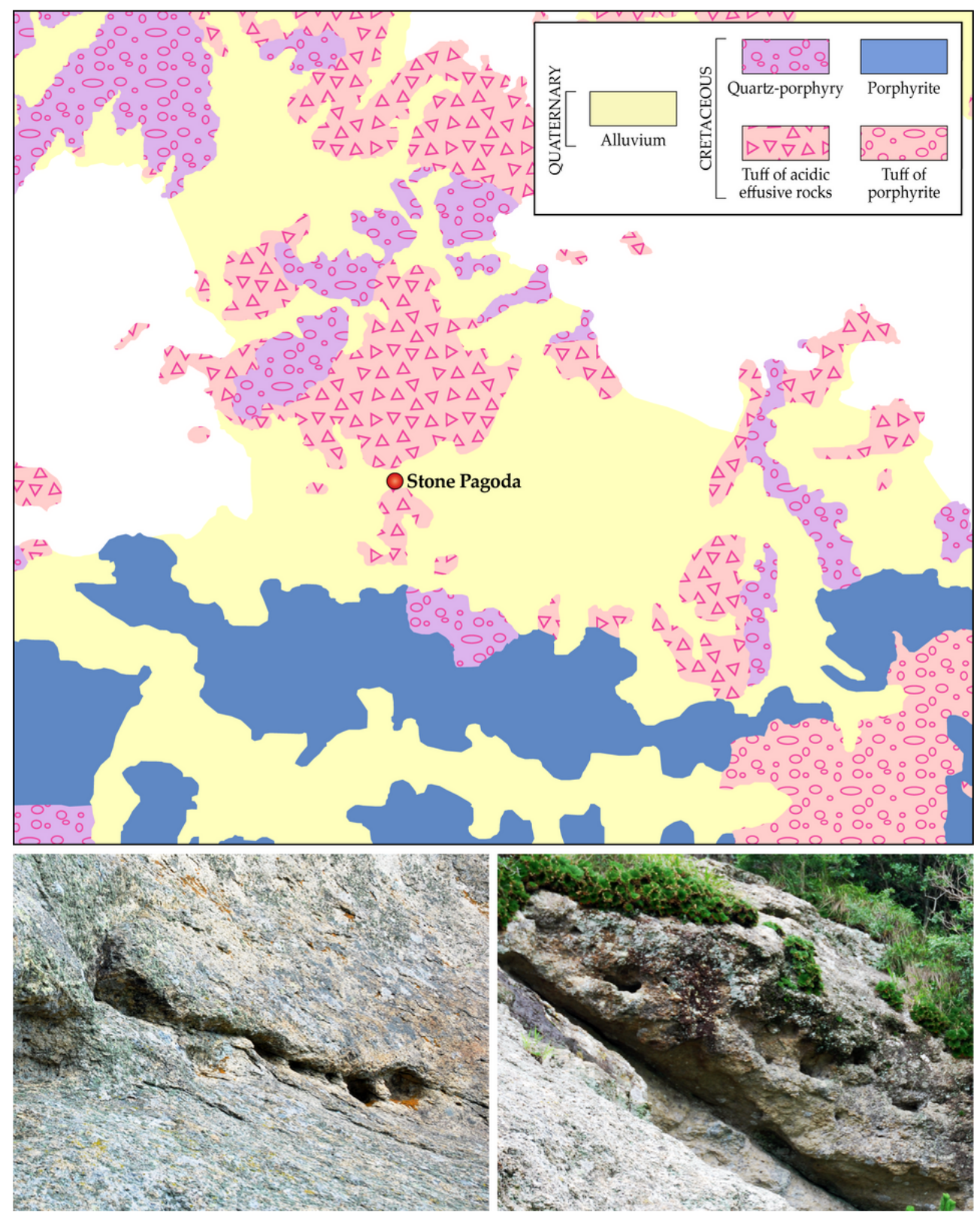

Figure 2

Geology of the area around the stone pagoda and quarrying traces observed in Geumgolsan Mountain. 

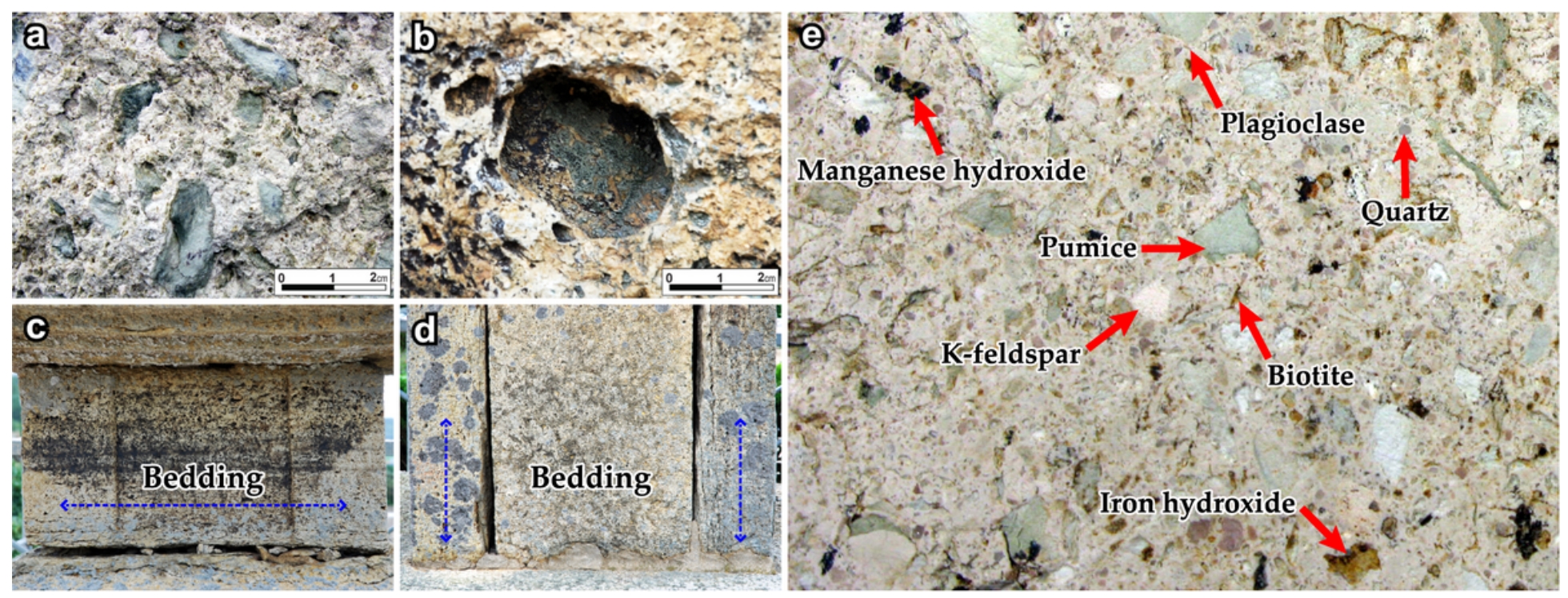

Figure 3

Photographs showing lithological features of the stone pagoda. (a) Lithic tuff containing light green pumice of various sizes. (b) Pumice detached from the original rock. (c) Horizontal bedding structure of lithic tuff. (d) Vertical bedding structure and microcracks distributed around the structure. (e) Petrographic features of the stone pagoda based on a slab analysis.
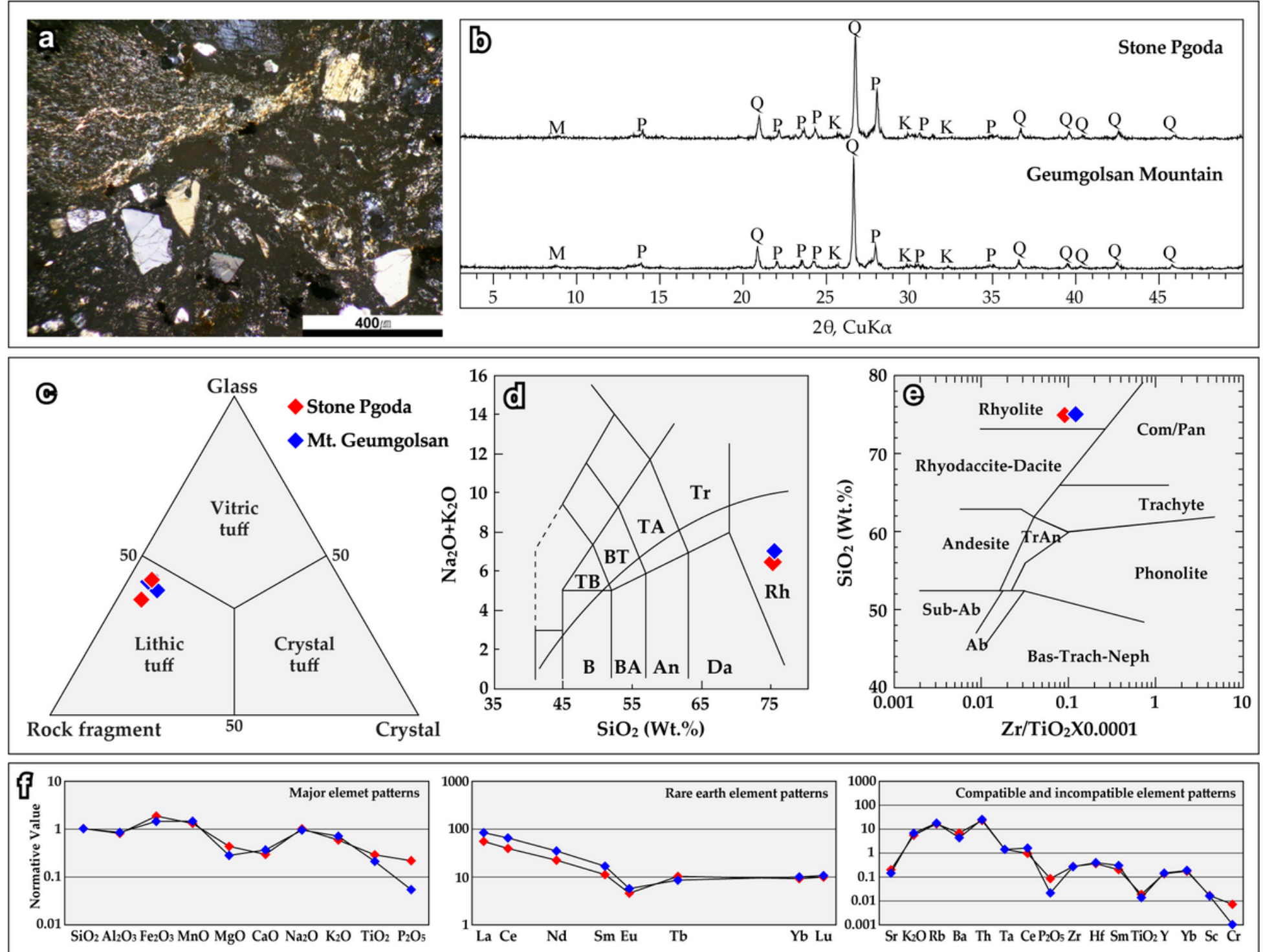


\section{Figure 4}

Mineralogical and geochemical characteristics of the stone pagoda and Geumgolsan Mountain. $(a, b)$ Mineral composition analysis by using a polarizing microscope and X-ray diffraction. (c) Modal analysis results based on the mineral composition. (d, e) TAS and $\mathrm{SiO} 2-(\mathrm{Zr} / \mathrm{TiO} 2 \times 0.001)$ classification diagrams. (f) Geochemical behavior characteristics of major, rare earth, and compatible and incompatible elements.

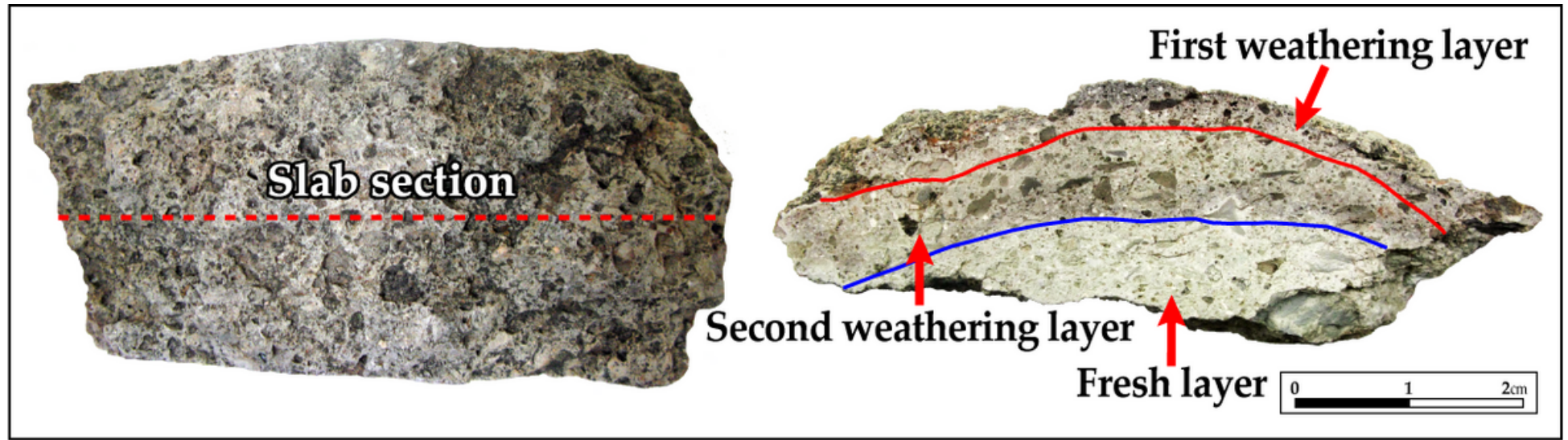

Figure 5

Slab cross-sectional analysis of the weathered lithic tuff.

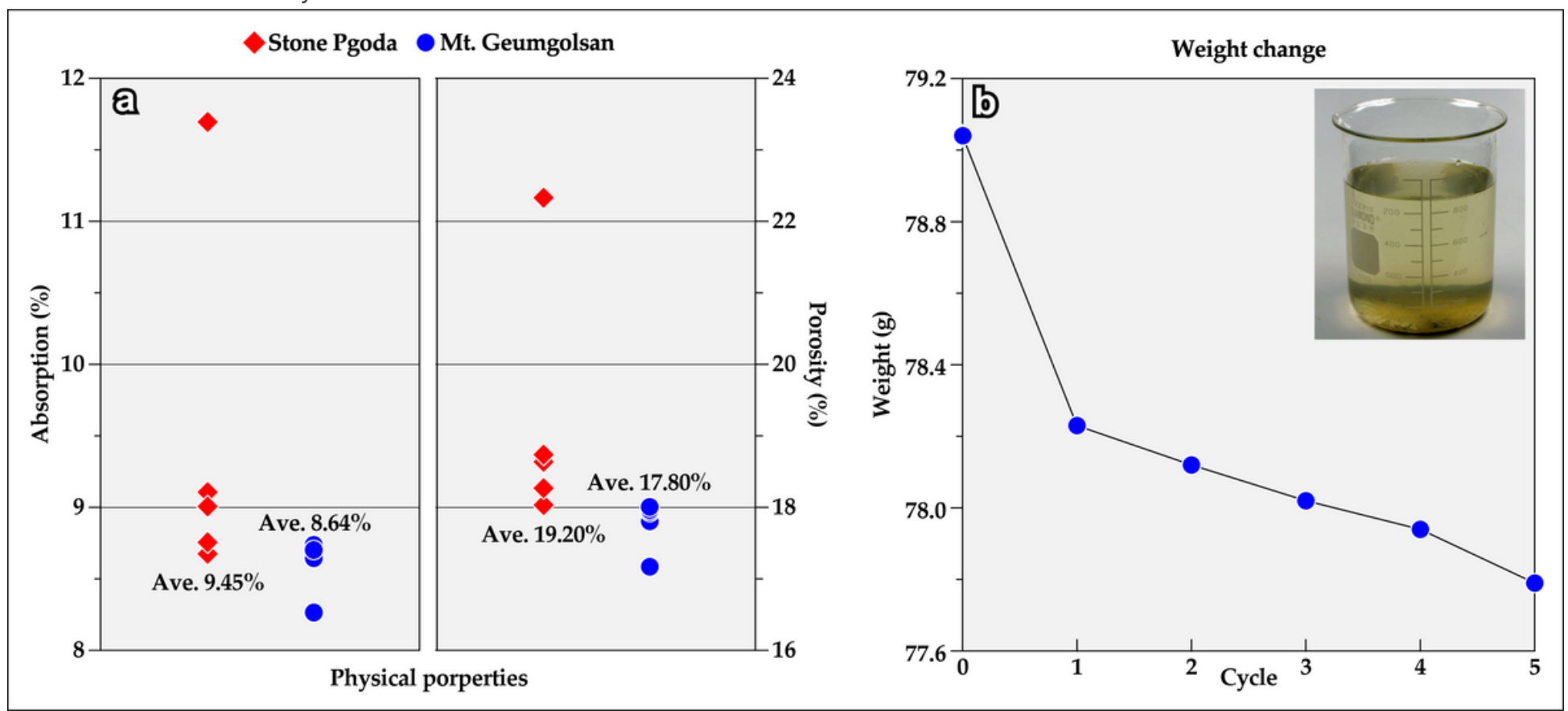

Figure 6

Physical properties of the lithic tuff of the stone pagoda and Geumgolsan Mountain. (a) Comparison of the water absorption rate and porosity. (b) Change in weight of fresh lithic tuff submerged in distilled water. 

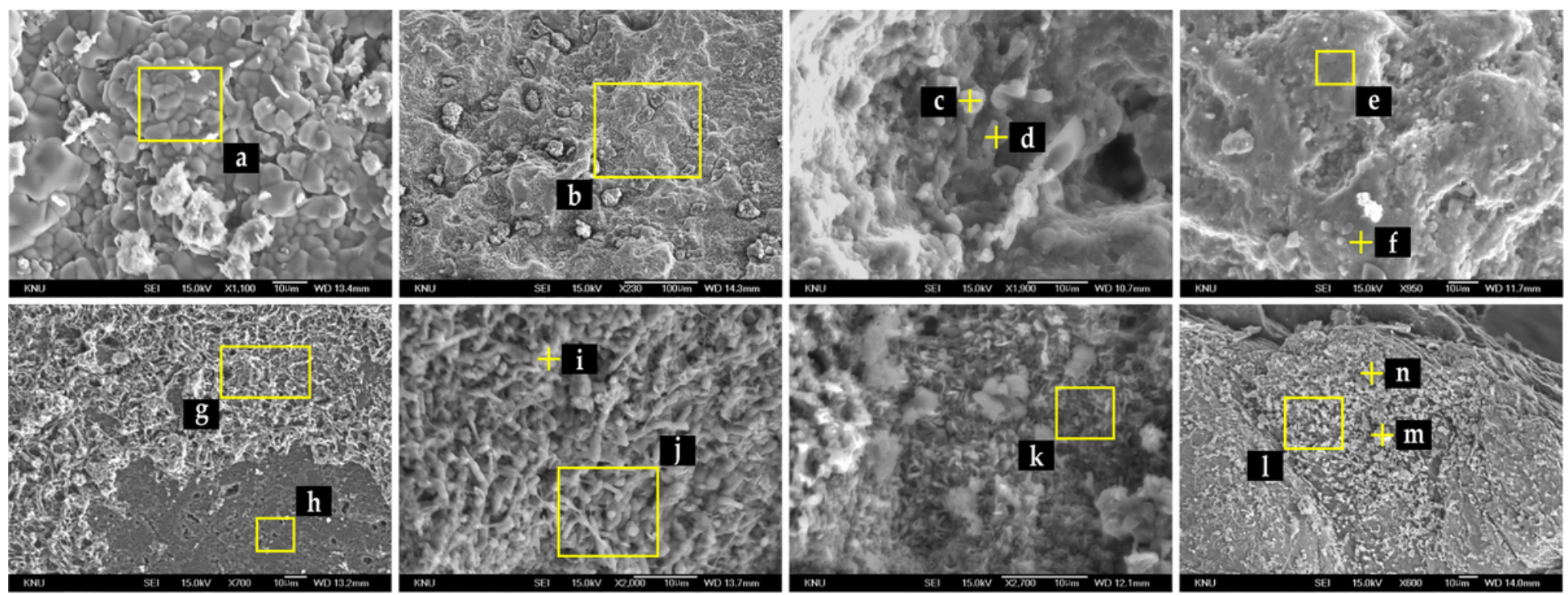

\section{Figure 7}

Scanning electron microscopy images and energy-dispersive spectrometry analysis points for blackened samples of the stone pagoda.
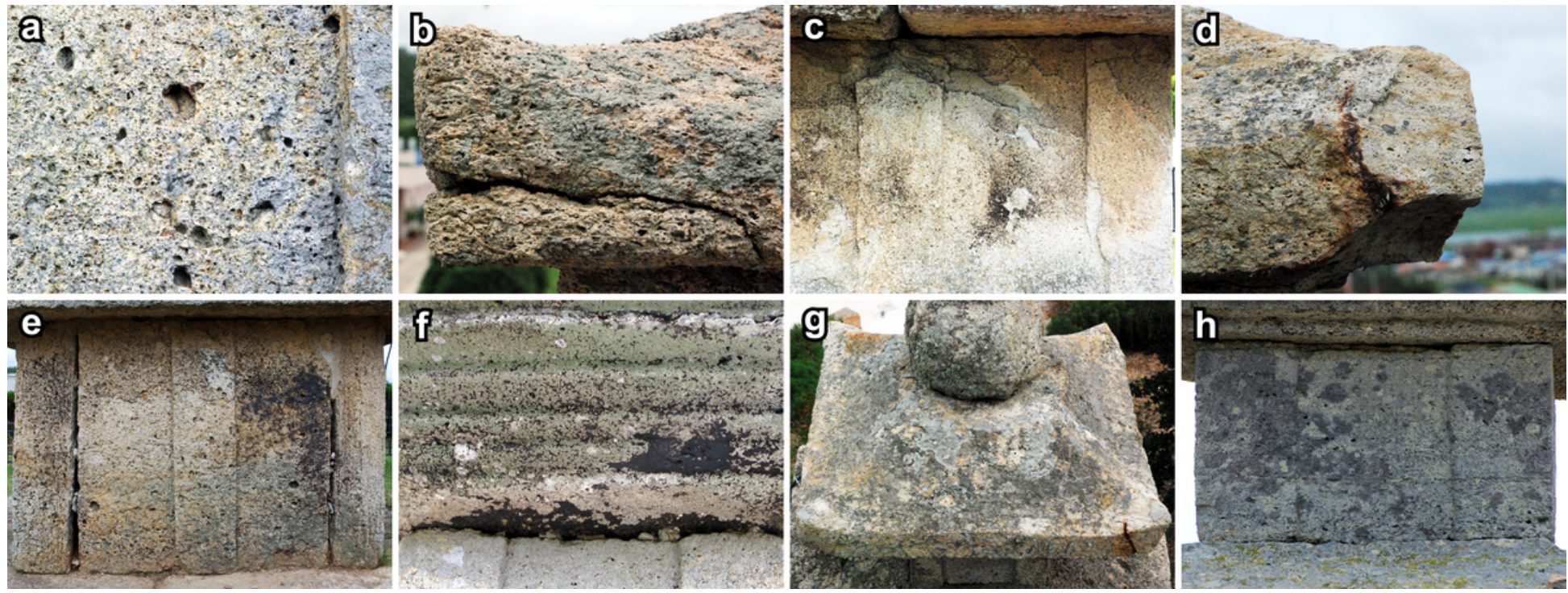

\section{Figure 8}

Conservation conditions of the stone pagoda. (a) Detachment of pumice fragments in a wide variety of sizes. (b) Structural crack on the south side of the fourth-story roof. (c) Three- to five-layer scaling of the south basement. (d) Fragmentation of the roof stone. (e, f) Brown and black discoloration caused by mineralogical weathering and diverse secondary contaminants. (g, h) Biological colonization observed throughout the stone pagoda. 


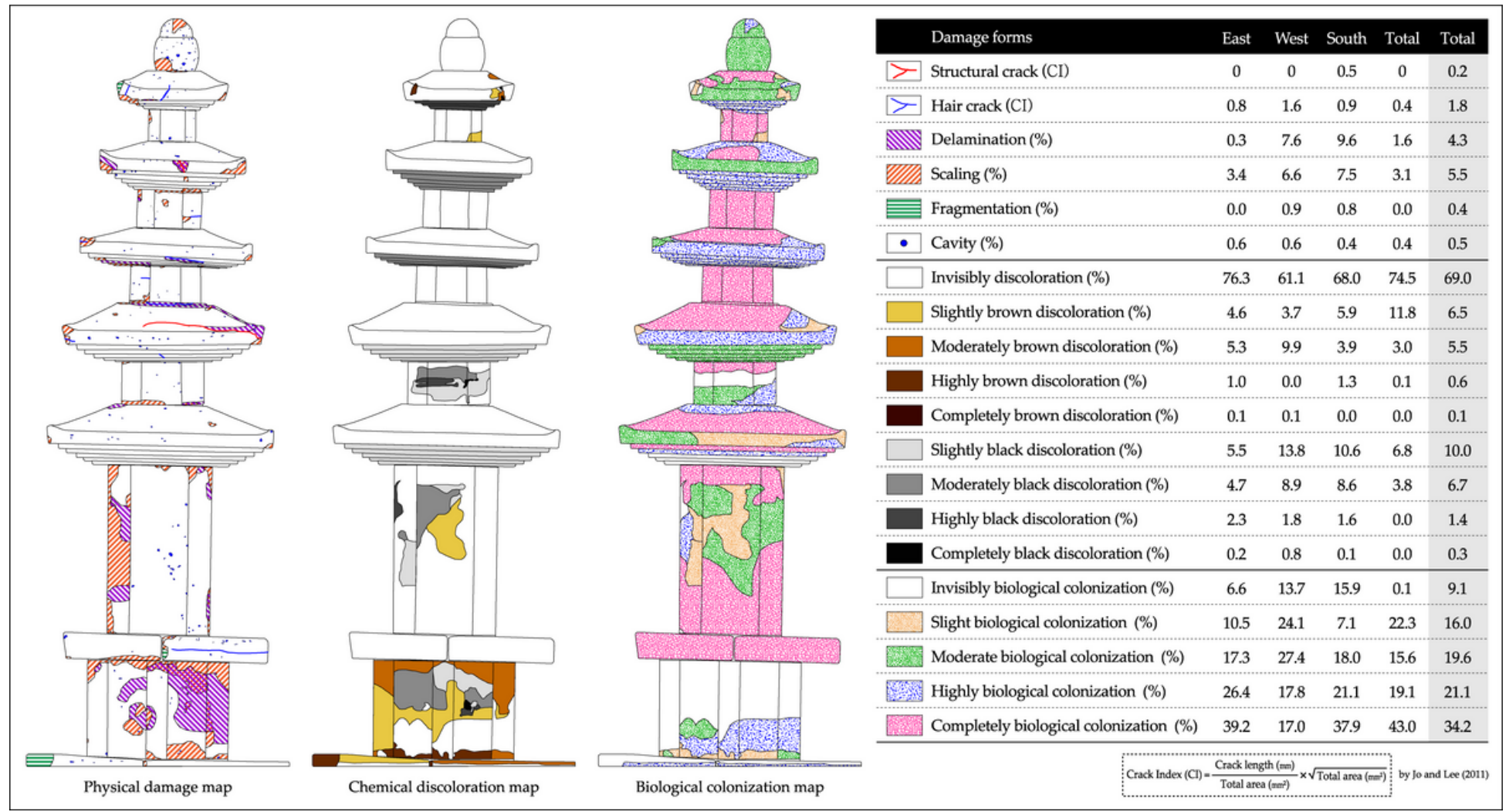

Figure 9

Damage maps and quantitative evaluation of a representative face (south) of the stone pagoda.

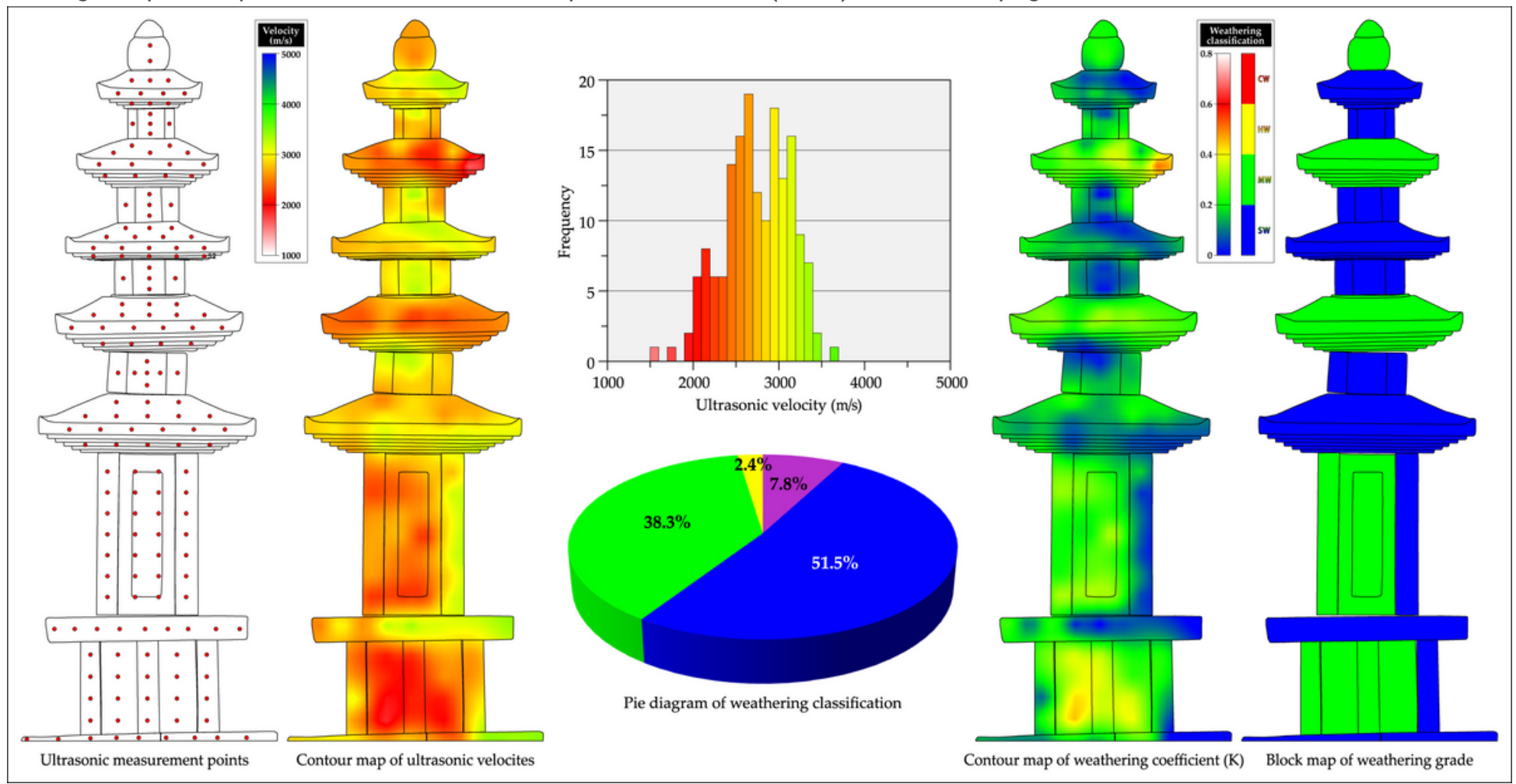

Figure 10

Ultrasonic measurement of a representative face (east) of the stone pagoda. 